\title{
Protective effect of porcine placenta in a menopausal ovariectomized mouse
}

\author{
Na-Ra Han, Chan-Lee Park, Na-Rae Kim, Hee-Yun Kim, Myoung-Schook Yoou, \\ Sun-Young Nam, Phil-Dong Moon, Hyun-Ja Jeong ${ }^{1}$ and Hyung-Min Kim \\ Department of Pharmacology, College of Korean Medicine, Kyung Hee University, 26, Kyungheedae-ro, \\ Dongdaemun-gu, Seoul 130-701, Republic of Korea and ${ }^{1}$ Department of Food Technology, Inflammatory Disease \\ Research Center, Hoseo University, 20, Hoseo-ro 79beon-gil, Baebang-eup, Asan, Chungcheongnam-do 336-795, \\ Republic of Korea
}

Correspondence should be addressed to H-M Kim; Email: hmkim@khu.ac.kr or to H-J Jeong; Email: hjjeong@hoseo.edu

The journal and the authors apologise for an error in the section on Preparation of PPE, Arg and $17 \beta$-estradiol in this article published in the September 2015 issue (vol 150 pp 173-181). Lyophilized powder of porcine placenta should read as Enzyme hydrolyzed powder of porcine placenta. The corrected section is published in full below:

\section{Preparation of PPE, Arg, and 17ß-estradiol}

Enzyme hydrolyzed powder of porcine placenta was obtained from Cellamedic Korea Co. (Seoul, Republic of Korea), dissolved in distilled water (DW), filtered with $0.22 \mu \mathrm{m}$ syringe filter, and prepared at doses of $0.1,1$, and $10 \mu \mathrm{g} / \mathrm{ml}$ according to a previous report (Han et al. 2013). Arg (Sigma Chemical Co.) was also dissolved in DW, filtered with $0.22 \mu \mathrm{m}$ syringe filter, prepared at a dose of $10 \mu \mathrm{g} / \mathrm{ml}$ according to a previous report (Han et al. 2013). 17ß-estradiol $\left(E_{2}\right.$, Sigma Chemical Co.) was dissolved in dimethyl sulfoxide, filtered with $0.22 \mu \mathrm{m}$ syringe filter, prepared at a dose of $100 \mathrm{nM}$ according to a previous report (Choi et al. 2011). 